\title{
Report of a consensus meeting on human brain temperature after severe traumatic brain injury: its measurement and management during pyrexia
}

\author{
Charmaine Childs ${ }^{1}{ }^{*}$,Tadeusz Wieloch ${ }^{2}$, Fiona Lecky ${ }^{3}$, Graham Machin ${ }^{4}$, Bridget Harris ${ }^{5}$ and Nino Stocchetti ${ }^{6}$ \\ 1 Yong Loo Lin School of Medicine, National University of Singapore, Singapore \\ 2 Laboratory for Experimental Brain Research, Wallenberg Centre for Neuroscience, Lund, Sweden \\ ${ }_{3}^{3}$ Trauma Audit Research Network, Salford Royal NHS Foundation Trust, University of Manchester, Greater Manchester, UK \\ 4 Temperature Group, National Physical Laboratory, Middlesex, UK \\ ${ }^{5}$ School of Clinical Sciences and Community Health, Royal Infirmary, The University of Edinburgh, Edinburgh, UK \\ ${ }_{6}^{6}$ Terapia Intensiva Neuroscienze, Ospedale Policlinico, Istituiti di Ricovero e Cura a Carattere Scientifico, Milano, Italy
}

\section{Edited by:}

Marten Risling, Karolinska Institutet, Sweden

\section{Reviewed by:}

Mattias Sköld, Karolinska Institutet, Sweden

Guy Clifton, Uniformed University of the Health Sciences, USA

${ }^{*}$ Correspondence:

Charmaine Childs, Yong Loo Lin School of Medicine, Alice Lee Centre for Nursing Studies, National University of Singapore, Block E3A, Level 3, 7 Engineering Drive 1, Singapore 117574. e-mail: charmaine_childs@nuhs.edu.sg
Temperature disturbances are common in patients with severe traumatic brain injury. The possibility of an adaptive, potentially beneficial role for fever in patients with severe brain trauma has been dismissed, but without good justification. Fever might, in some patients, confer benefit. A cadre of clinicians and scientists met to debate the clinically relevant, but often controversial issue about whether raised brain temperature after human traumatic brain injury (TBI) should be regarded as "good or bad" for outcome. The objective was to produce a consensus document of views about current temperature measurement and pyrexia treatment. Lectures were delivered by invited speakers with National and International publication track records in thermoregulation, neuroscience, epidemiology, measurement standards and neurocritical care. Summaries of the lectures and workshop discussions were produced from transcriptions of the lectures and workshop discussions. At the close of meeting, there was agreement on four key issues relevant to modern temperature measurement and management and for undergirding of an evidence-based practice, culminating in a consensus statement. There is no robust scientific data to support the use of hypothermia in patients whose intracranial pressure is controllable using standard therapy. A randomized clinical trial is justified to establish if body cooling for control of pyrexia (to normothermia) vs moderate pyrexia leads to a better patient outcome forTBI patients.

Keywords: brain temperature, measurement, pyrexia, fever, cooling

\section{INTRODUCTION}

\section{PYREXIA AFTER TRAUMATIC BRAIN INJURY: IS IT GOOD OR BAD FOR PATIENT OUTCOME?}

For patients with severe traumatic brain injury (TBI) temperature management is undertaken for two reasons; (a) for neuroprotection (b) for control of pyrexia. In the case for cerebral neuroprotection, results in rodents provide convincing evidence that if body (or brain) temperature is lowered such that animals are rendered hypothermic during a brief period of transient cerebral ischemia, infarct size is smaller compared to the "normothermic" or hyperthermic animal (Busto et al., 1987; Kim et al., 1996; Yanamoto et al., 1999). The starting point to begin hypothermic neuroprotection may well be a normal temperature (which in the rat under thermoneutral conditions is $38^{\circ} \mathrm{C}$ Stoner, 1974). Hypothermia holds promise as a neuroprotective therapy after ischemic stroke (Lyden et al., 2006) but as the role of ischemia remains controversial as a mechanism of brain damage after TBI (Coles, 2004; Vespa, et al., 2005) the benefit of hypothermia for neuroprotection in this patient group remains speculative (Abate et al., 2008).

To date there is no robust evidence that control of pyrexia, using antipyretic drugs or body cooling is beneficial after severe TBI. Nevertheless current opinion favors treatment for control of pyrexia
(Kilpatrick et al., 2000) because of the commonly held view that a mild to moderate rise in temperature is harmful (Manno and Farmer, 2004). We can add a third common assumption that, for all practical purposes, body temperature is an adequate surrogate measure of brain temperature even though there are well documented observations showing brain-body dissociation (Mellergard, 1994; Stone et al. 1995; Henker et al., 1998; Rumana et al., 1998; Childs et al., 2005).

Guidelines for the best approach to temperature measurement do not exist. The most recent (2007) Brain Trauma Foundation (BTF) recommendations for therapeutic hypothermia after TBI (Bullock and Povlishock, 2007) are based on the lowest level of evidence only (Cook et al., 1995; also refer to Center for Evidence Based Medicine www.cebm-net/). Until we can "close the loop" on our understanding of the impact of pyrexia on outcome (good or bad in the case of TBI patients; Childs, 2008) treatment will continue to be underpinned by weak, inconclusive evidence of benefit. This paper aims at summarizing current knowledge in the field and in particular two clinically relevant issues:

(a) In the critical care setting, what should future recommendations be: direct measurement of brain temperature or to continue using body core temperature surrogates? 
(b)Should therapeutic control of temperature be advocated as a treatment panacea or should it be "on prescription"?

\section{MANCHESTER CONSENSUS MEETING}

A cadre of clinician-scientists were invited to participate in a debate about the clinically relevant, but often controversial issue: "Is raised brain temperature; good or bad after human TBI?" Interlinked, "bench to bedside" lectures, were presented followed by workshop discussions, the content of which forms this consensus document.

\section{LITERATURE FRAMEWORK \\ WHAT ARE THE POSSIBILITIES FOR ACCURATE MEASUREMENT OF TEMPERATURE IN PATIENTS?}

The essential background role that calibration, traceability and accreditation play in ensuring reliable temperature measurement was discussed. Particular emphasis was given to ensuring measurements were reliably linked to the International temperature scale of 1990 (ITS-90; Preston-Thomas, 1990). ITS-90 is essentially a "recipe" of how to realize a temperature scale that is close to thermodynamic values through the calibration of specified thermometers (platinum resistance thermometers, PRTs) at defined temperature references known as fixed points. The primary fixed points are generally the freezing points of pure materials or triple points (e.g., of water). A triple point is a unique point on a materials phase diagram where solid, liquid, and vapor coexist. The calibrated PRT is then used as a reference for the calibration of other more "practical" sensors, e.g., in situ mini sensors of the type used in everyday health care practice. In addition, special radiance sources are constructed to derive their temperature from calibrated PRTs. These can be used to calibrate clinical infra-red (tympanic, temporal artery, thermal imaging) thermometers.

Using the triple point of two high performance organic fixedpoint temperature reference substances, Diphenyl-ether (DPE; nominally $26^{\circ} \mathrm{C}$ ), and ethylene carbonate (EC; nominally $36^{\circ} \mathrm{C}$ ), (both substances having temperature uncertainties of $0.005^{\circ} \mathrm{C}$ ) the performance (reliability, reproducibility, and measurement error) of clinical thermometers used for deep body temperature measurement were tested for traceability of the thermometers to ITS-90 and for maximum confidence in the measurements. The results showed that all the temperature sensors tested (brain and core body thermistors) performed within the manufacturer's stated tolerances (Childs and Machin, 2009; Machin and Childs, 2010).

In recent years, new techniques have emerged for non-invasive temperature measurement. Proton magnetic resonance spectroscopy ( $\left.{ }^{1} \mathrm{HMRS}\right)$ can be utilized for absolute internal temperature (Childs et al., 2007). However, there is currently no established approach to calibrate measurements in a systematic way but two independent temperature measurement techniques can be used for MR thermometry: PRTs and phantom-based, organic triple point, temperature cells. Early results and field trials are promising (Vescovo et al., 2010). A novel, quasi-spherical, temperature phantom has been developed and built suitable for use at field strengths of 1.5 and 3 Tesla "phantom" material is placed at the center, surrounded by a reference source of the organic fixedpoint material, which for clinical measurement consists of either DPE or EC.

\section{THE ROLE OF TEMPERATURE IN THE DAMAGED BRAIN}

In most animal species, the response to local and systemic inflammation and infection is a rise in body temperature. Fever, with its long evolutionary history has been shown to confer benefit for the host in terms of bacterial killing and increased immunity. Over the years, studies have been conducted in numerous species (Kluger, 1979) and the survival benefit of fever is evident (Romanovsky and Szekely, 1998). It is also clear that mortality increases if the febrile response to inflammation is prevented or blocked (Griesman and Mackowiak, 2002; Schulman et al., 2005).

In patients, fever is a common sign of inflammation and trauma and for the most part is widely thought to have a beneficial role in "fighting" infection. However, if the injury damages brain (and specifically ischemic cells) tolerance to heat is low (Brinnel et al., 1987). The prevailing view in neurocritical care rather favors the opinion that raised temperature after TBI is bad and that low temperature is innocuous and beneficial.

Studies in animals show that below normal temperature preserves, and high temperature accelerates damage in ischemic neurones (Yanamoto et al., 1999). There is evidence to support the case for therapeutic neuroprotection by induction of hypothermia in ischemic brain (cardiac arrest; Lyon et al., 2010) and neonatal hypoxic encephalopathy (Shankaran et al., 2008) but the evidence is not as compelling after human stroke (Schwab et al., 1998) and the value of mild or moderate hypothermia remains speculative in patients with brain trauma (Sydenham et al., 2009). On balance therefore, the view is that raised temperature due to fever has biological benefit if the brain is intact but once damaged (specifically by ischemia) any protective benefits of a "true" fever may be outweighed by the presumed increased vulnerability of CNS tissue to damage by heat (Haveman et al., 2005; Van Der Zee et al., 2008).

The uncertainty about the role of fever after TBI presents a dilemma for the clinician. How can appropriate evidence-based decisions be made when there is a lack of robust data to underpin practice? Which patients should be a priority for treatment of pyrexia and which patients are at low risk of temperature-related secondary damage? With the increasing interest and use of therapeutic hypothermia, even in the absence of clear benefit, at least in humans we may now need to question the potential for "good" and "bad" effects of deliberate hypothermia, as well as the potentially "good" and "bad" effects of fever (Clifton et al., 2001; Hutchinson et al., 2008). Since there is an abundant literature on the use of therapeutic hypothermia, still without a definitive answer about its benefits, it is timely to give thought to the apparently "unthinkable"; that there may be TBI patients for whom a moderate rise in temperature might not be harmful and who might not need aggressive temperature control.

\section{TEMPERATURE AS A MARKER OF SECONDARY BRAIN DAMAGE}

Of the many factors contributing to the quality of a patient's outcome after TBI, body temperature has only recently been considered for its prognostic significance. The problem is that any relationship between body (or brain) temperature, particularly with respect to sub-normal temperature and outcome is confounded by other important variables such as brain injury severity, age, gender, peripheral trauma, and a number of co-existing physiological responses (e.g., pupil size, intracranial pressure). At 
the time of admission, approximately $10 \%$ of patients presenting with TBI were hypothermic (McHugh et al., 2007). From results of the International TBI data collaboration on modeling prognostic indicators of outcome after TBI (IMPACT; Maas et al., 2007), it was recognized that any relationship between (brain) temperature and outcome would be confounded by other important variables (if not measured and adjusted for). During the years spanning 1982-1998, the IMPACT methods were to merge data from randomized trials and large observational studies of TBI patients treated in an ICU setting. Univariate analysis of 26 predictors for outcome at 6 months were analyzed in 8719 patients. Hypoxia, hypotension, and spontaneous hypothermia were significant prognostic markers of adverse outcome. However, the strength of the association between hypothermia on admission to the Emergency Department (ED) and adverse outcome after TBI was lessened after adjustment for other confounders such as age, GCS, motor score and pupil size and reactivity. In view of the results, the adverse outcomes associated with spontaneous hypothermia do not lend support for "continued" body cooling of the TBI patient on arrival to the ED and before transfer to ICU. Despite the large numbers of patients studied from the IMPACT database, there is still uncertainty about how best to manage body temperature after acute TBI.

\section{IS THERAPEUTIC HYPOTHERMIA A DOUBLE-EDGE SWORD?}

From studies of experimental ischemia in rodents, the mechanisms of neuroprotection by hypothermia appear to be multifactorial. The degree of neuroprotection afforded will depend on the severity of the insult and the timing, depth and duration of hypothermia after the onset of cerebral ischemia. As the pathological mechanisms involved are known to be complex, they may of themselves act as a double-edged sword, having both beneficial and deleterious effects on the ischemic animal brain (Endress et al., 2008). Of the biochemical pathways involved in "hypothermia-induced neuroprotection," glutamate and calcium ions are major players in neuronal excitotoxicity but they are also essential for normal brain function and a key driving force for the reorganization and synaptogenesis involved in tissue repair after injury (Wieloch and Nikolich, 2006). In this same vein, nitric oxide (NO) derived from endothelia may increase blood flow, so aiding healing, whilst neuronal and inducible NO synthase (NOS) may contribute to inflammation with the formation of oxidants and free radicals. This raises questions about whether or not hypothermia (which may act to ameliorate inflammation) is exclusively beneficial. Perhaps at times hypothermia could be disadvantageous (Goss et al., 1995). Hypothermia might be protective early during recovery but if induced later, might impede repair.

From the point of view of effects on coagulation, hypothermia is regarded as a major risk factor for morbidity and mortality. It is a well recognized supposition that free blood in the ventricles after subarachnoid hemorrhage may play a role in vasospasm and development of high fever (Grande et al., 2009). However, whilst experimental hypothermia $\left(32^{\circ} \mathrm{C}\right)$ has been shown to inhibit coagulation function in swine (Martini, 2007) and in hypothermic $\left(33.8^{\circ} \mathrm{C}\right)$ post-laparotomy surgical patients with blood loss (Bernabei et al., 1992) the induction of hypothermia after severe TBI in patients with comparable $\left(33^{\circ} \mathrm{C}\right)$ body temperature did not show a significant difference in coagulation parameters (although a tendency toward lower platelet counts was observed in the hypothermic group) compared to normothermic patients (Tokutomi et al., 2004).

\section{PYREXIA: HOW DOES IT INFLUENCE BRAIN OXYGENATION AND CHEMISTRY?}

Altered temperature is a sign of inflammation rather than a disease itself. What seems certain in the light of the recent studies is that high temperature after TBI is common, especially in those presenting with a GCS of 9 or less (Stocchetti et al., 2002). The threshold for fever has been widely debated but practice parameters for evaluating new fever onset in critical care developed by O'Grady et al. (1998) allow a level of uniformity in describing fever. Stocchetti et al. (2005) show that $78 \%$ of patients had temperatures above $38.3^{\circ} \mathrm{C}$, the Critical Care Society threshold for fever, despite antibiotic and antipyretic treatment. Pyrexia had a significantly different distribution depending on the severity of damage, with patients with the most severe brain trauma more likely to have an early and consistent pyrexia than those patients with GCS $>8$. Pyrexia prolonged the length of ICU stay (LOS).

For apyrexial patients, LOS was an average of 8 days whereas pyrexial patients stayed in ICU for significantly longer (average 14 days). An important concern with regard to the impact of raised temperature after TBI is that of effects on intracranial pressure (ICP). Although Rossi et al. (2001) were unable to show a clear relationship between average ICP and brain temperature (a finding supported recently from the groups of LeRoux's (Spiotta et al., 2008) and Childs et al. (2009) it was noted, that during the febrile episode, ICP was significantly increased. That a rise in brain temperature during fever was accompanied by a rise in ICP (and concomitant increase in $\mathrm{SjO}_{2}$ ) may suggest that the increase in brain temperature has effects more on increasing CBF (and possibly cerebral blood volume) than it does on increasing cerebral metabolism $\left(\mathrm{CMRO}_{2}\right)$. The limited number of patients studied and the lack of direct cerebral blood flow monitoring make it possible only to suggest (from the $\mathrm{SJO}_{2}$ measurements) that a mismatch between $\mathrm{CBF}$ and $\mathrm{CMRO}_{2}$ may be occurring during fever. Of course the rise in ICP and temperature may be epiphenomenon of different inflammatory processes or due to effects of raised temperature per se, possibly due to mechanisms other than "true" fever. Here "central" fever or neurogenic hyperthermia due to damage to the central thermoregulatory pathways may precipitate cerebral oedema as temperature exceeds $40^{\circ} \mathrm{C}$. As Cremer and Kalkman (2007) suggest, neurological abnormalities of a temperature increase above the fever threshold, which has long been regarded to be $41^{\circ} \mathrm{C}$ (DuBois, 1949), is associated with disturbed conscious level, brain oedema, and a high mortality. The possibility of a combination of pathological events linking raised temperature with brain swelling and intracranial hypertension has been observed in rodents (Sharma and Hoopes, 2003).

Significant reductions in mean brain tissue oxygen content $\left(\mathrm{PbtO}_{2}\right)$ occur as brain temperature is lowered from $37^{\circ} \mathrm{C}$ to $34^{\circ} \mathrm{C}$. Gupta et al. (2002) however show that at temperatures within the normal to moderate fever range $\left(37-38.9^{\circ} \mathrm{C}\right) \mathrm{PbtO}_{2}$ is relatively unchanged. More recent data lends further support to the view that raised brain temperature does not bring about a reduction in brain tissue oxygen (Spiotta et al., 2008). Using commercially available systems (Licox, Integra Neuroscience, Plainsboro, NJ, USA) for brain tissue partial 
pressure of oxygen overall brain temperature and brain tissue oxygen were poorly correlated suggesting that the relationship between human brain temperature and brain oxygen is complex.

Against this background of uncertainty about the role of raised temperature; whether it could be harmful to injured neurones or whether it could be an adaptive response and therefore of some benefit to the patient, the impact of pyrexia on neurochemistry and cerebral oxygenation after acute brain injury was presented. Brain tissue temperature, partial pressure of oxygen (Licox Systems, Integra Neurosciences, Plainsboro, NJ, USA) and microdialysis (CMA, Sweden) for brain glucose, lactate, pyruvate, and glutamate were measured in a mixed neurocritical care population. Despite a rise in brain temperature of the order of $1.3^{\circ} \mathrm{C}$, no significant changes from baseline in any of the measured variables (including ICP, CPP, brain tissue $\mathrm{pH}, \mathrm{CO}_{2}$, glucose, lactate, pyruvate, ratio) were observed. However it was noted that brain tissue oxygen partial pressure (reflecting the balance between cerebral oxygen delivery and consumption) rose significantly and the arterio-venous difference in oxygen content $\left(\mathrm{AJDO}_{2}\right)$ dropped significantly from 4.2 to 3.8 vol\% $(p<0.05)$. These data suggest that oxygen supply to the brain during fever in patients with non-ischemic brain trauma (TBI) remains adequate during the febrile event.

Appropriate, and safe, translation of research evidence obtained in experimental studies to the patient is of key importance for evidence-based practice (Sacho and Childs, 2008). Despite the weight of opinion that raised temperature is both frequent and harmful, results from Stocchetti's group showing that a rise in average brain temperature (from 38 to $39^{\circ} \mathrm{C}$ ) was not associated with abnormal neurochemistry requires an explanation particularly as pyrexia appeared to be well tolerated in the small patient population studied and, furthermore, did not exacerbate ICP readings (Table 1). This is of particular importance currently, in view of the recent evidence that many of the treatments used to lower the temperature of the body are associated with adverse side effects (Seule et al., 2009). In the current clinical climate, translational medicine is pivotal in establishing: (a) whether results obtained in one clinical pathology (e.g., stroke) translate to other clinical conditions (e.g., severe brain trauma) and (b) whether studies in animals are an appropriate model for safe translation of results from the bench to the bedside.

\section{BRAIN TEMPERATURE AND OUTCOME AFTER TBI: TRACING THE EVIDENCE FROM BENCH}

Although new possibilities for non-invasive temperature measurement are on the horizon, the day to day delivery of accurate estimation of body, and in the case of brain trauma, brain tissue temperature, remain one of the most common clinical measurement activities. Despite the interest in temperature and outcome after TBI, there is no universal definition of the threshold for an increased temperature or where and how temperature should be measured. The European Brain Injury Consortium guidelines recommend avoiding hyperthermia but do not define this (Maas et al., 1997). The most recent Brain Trauma Foundation Guidelines do not mention fever thresholds or discuss the management of increased temperature [except in the context of hypothermia (level III recommendation only); Cook et al., 1995]. In practice most clinicians contend that normothermia is beneficial after TBI and, anecdotally, in the view of some, therapeutic hypothermia is warranted. However, Aiyagari and Diringer in a recent systematic review of fever control in brain injury concluded that: “... the answer to the critical question: Does fever control improve outcome is not known?”. The definitive study has not been performed (Aiyagari and Diringer, 2007). Two recent systematic reviews of therapeutic hypothermia for TBI have not shown clear benefit (Peterson et al., 2008; Sydenham et al., 2009). On this basis, decisions about how best to approach the management of temperature have not achieved equipoise.

Even so, current opinion is that raised temperature after TBI is associated with worse outcome. There is some support for this view in a recent systematic review and meta-analysis on pooled data from patients with stroke and TBI (Greer et al., 2008). However, only 17\% of the patient cohort had TBI. Of the eight adult TBI studies, four failed to show a significant relationship between temperature and mortality (Jeremitsky et al., 2003; Geffroy et al., 2004, (and Glasgow Outcome Score, GOS), Andrews et al., 2002; Soukup et al., 2002). The relationship between temperature and outcome after TBI may not be entirely clear cut as shown recently in an observational study of the relationship between temperature and outcome in patients with severe TBI (Childs et al., 2006).

In the relationship between temperature and outcome there are potentially confounding factors such as severity of injury (Jeremitsky et al., 2003) and, because temperature is a symptom,

Table 1 | Changes in intracranial pressure, cerebral perfusion pressure, $\mathrm{pH}$, and jugular bulb oxygen saturation before and after the development of pyrexia.

\begin{tabular}{|c|c|c|c|c|c|c|c|c|c|c|}
\hline & \multicolumn{5}{|c|}{ Fever onset } & \multicolumn{5}{|c|}{ Fever lysis } \\
\hline & $\begin{array}{l}\text { ICP } \\
(\mathrm{mmHg})\end{array}$ & $\begin{array}{l}\text { CPP } \\
(\mathrm{mmHg})\end{array}$ & $\begin{array}{l}\mathrm{Pb}_{\mathrm{t}} \mathrm{O}_{2} \\
(\mathrm{mmHg})\end{array}$ & $\mathrm{pH}_{\mathrm{br}}$ & $\mathrm{SJO}_{2}$ & $\begin{array}{l}\text { ICP } \\
(\mathrm{mmHg})\end{array}$ & $\begin{array}{l}\text { CPP } \\
(\mathrm{mmHg})\end{array}$ & $\begin{array}{l}\mathrm{Pb}_{\mathrm{t}} \mathrm{O}_{2} \\
(\mathrm{mmHg})\end{array}$ & $\mathrm{pH}_{\mathrm{br}}$ & $\mathrm{SJO}_{2}$ \\
\hline Baseline $\left(T_{\mathrm{br}} 38.0^{\circ} \mathrm{C}\right)$ & $16(4)$ & $71(10)$ & $32(21)$ & $7.19(0.06)$ & $0.69(0.05)$ & & & & & \\
\hline Pyrexia $\left(T_{b r} 39.3^{\circ} \mathrm{C}\right)$ & $17(6)$ & $71(100)$ & $37(22)^{*}$ & $7.16(0.06)$ & $0.71(0.06)$ & & & & & \\
\hline Pyrexia $\left(T_{\mathrm{br}} 39.2^{\circ} \mathrm{C}\right)$ & & & & & & $18(6)$ & $71(6)$ & $24(14)$ & $7.10(0.09)$ & $0.70(0.05)$ \\
\hline
\end{tabular}

Table adapted from Stocchetti et al. (2005)

Data (baseline to fever onset, $n=14$ ). Data expressed as mean (SD)

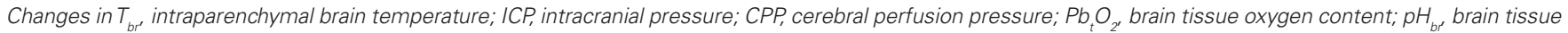
$\mathrm{Ph}$; and $\mathrm{SJO}_{2^{\prime}}$ jugular saturation at the superior jugular bulb in 13 patients with severe TBI before (baseline) and on developing fever (pyrexia).

${ }^{*} p<0.05$ vs baseline, ${ }^{* *} p<0.001$ vs pyrexia. Note the significant increase in $\mathrm{Pb}_{t} \mathrm{O}_{2}$ with pyrexia. 
the reason(s) for a rise in temperature may include the acute inflammatory response to injury, infection and/or neurogenic fever (Thompson et al., 2003). The problem is that the underlying cause of raised temperature may be impossible to determine with certainty. Furthermore, there is likely to be a complex interplay with other influences on temperature, for example hypotension, blood sugar, hydration, and sleep (Mekjavic and Eiken, 2006). Adding to the complexity of probing the root to the relationship between temperature and outcome is the variability in temperature site, the frequency of the measurement interval per se, the duration of temperature monitoring, the frequency of raised (or lowered) temperature, the use of therapeutic temperature interventions and the time-interval to follow-up and outcome assessments.

Decision tree analysis has been used to explore predictors of outcome at 12 months (Jones et al., 1994; McQuatt 1998; Andrews et al., 2002). Logistic regression analysis in a patient sub-set showed duration of pyrexia to be significantly associated with mortality at 12 months ( $p=0.014$; Jones et al., 1994). However the decision tree analysis for GOS prediction showed a small group of patients in whom "more" pyrexia was not associated with worse outcome, nor "less" pyrexia with better outcome (McQuatt, 1998). The emerging hypothesis from some of the decision trees is that pyrexia may not always be detrimental. Further assessment and investigation is warranted (Andrews et al., 2002).

These results are supported by data from our own group (CC) where burden of pyrexia (\% time spent with brain temperature $\geq 37.5^{\circ} \mathrm{C}$ ) during the period of intraparenchymal monitoring was significantly greater in survivors compared with non-survivors ( $p=0.02$; Figure 1). In the first of two observational studies, Childs

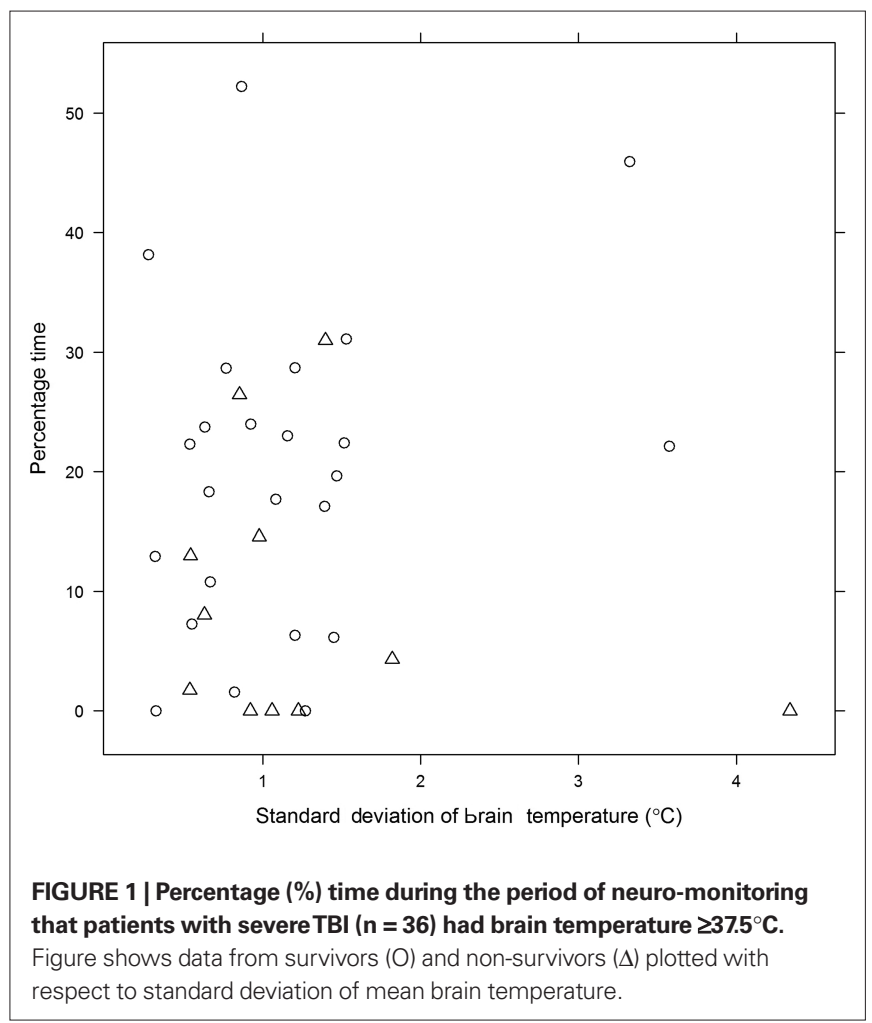

et al. (2006) (Figure 2), used logistic regression to explore for linear and quadratic relationships between initial (and $48 \mathrm{~h}$ average) brain temperature and survival at 3 months. No evidence of an association between initial brain temperature and risk of death was found. From statistical modeling, and assuming a linear relationship between brain temperature and death at 3 months, patients with higher mean brain temperature were less likely to die OR (95\% confidence interval, CI) for death per $1^{\circ} \mathrm{C}$ change in temperature was $0.31(0.09-1.1, p=0.06)$. On the other hand, fitting a quadratic relationship to the data suggested that low and high end temperatures were associated with an increased risk of death. Unlike studies in human stroke where high admission temperature predicts poor outcome (Reith et al., 1996), results in a population of severe TBI patients did not support such a relationship.

In our subsequent study of the temporal pattern of brain temperature, 35 of 67 patients with severe TBI had a brain temperature $>37.5^{\circ} \mathrm{C}$ for $60-100 \%$ of time during the first 5 days. Therapeutic temperature management with body cooling was minimal. There were four deaths only (11\%) in this "persistent pyrexia" group. More patients died in the group who did not develop pyrexia. Statistical modeling of the relationship between brain temperature and probability of death at 30 days revealed the lowest probability of death to be in patients with brain temperature in the range $36-38.5^{\circ} \mathrm{C}$. Taking in to account the severity of brain injury using pupil size and reactivity as a marker, the predicted probability of death increased as brain temperature dropped below $36^{\circ} \mathrm{C}$. For those patients with "abnormal" pupillary responses, the probability of death was rather constant across the range $34-39^{\circ} \mathrm{C}$ (Sacho et al., 2010). Small sample size limits the impact of the findings but even so, the results do raise important questions; not least the question of whether a

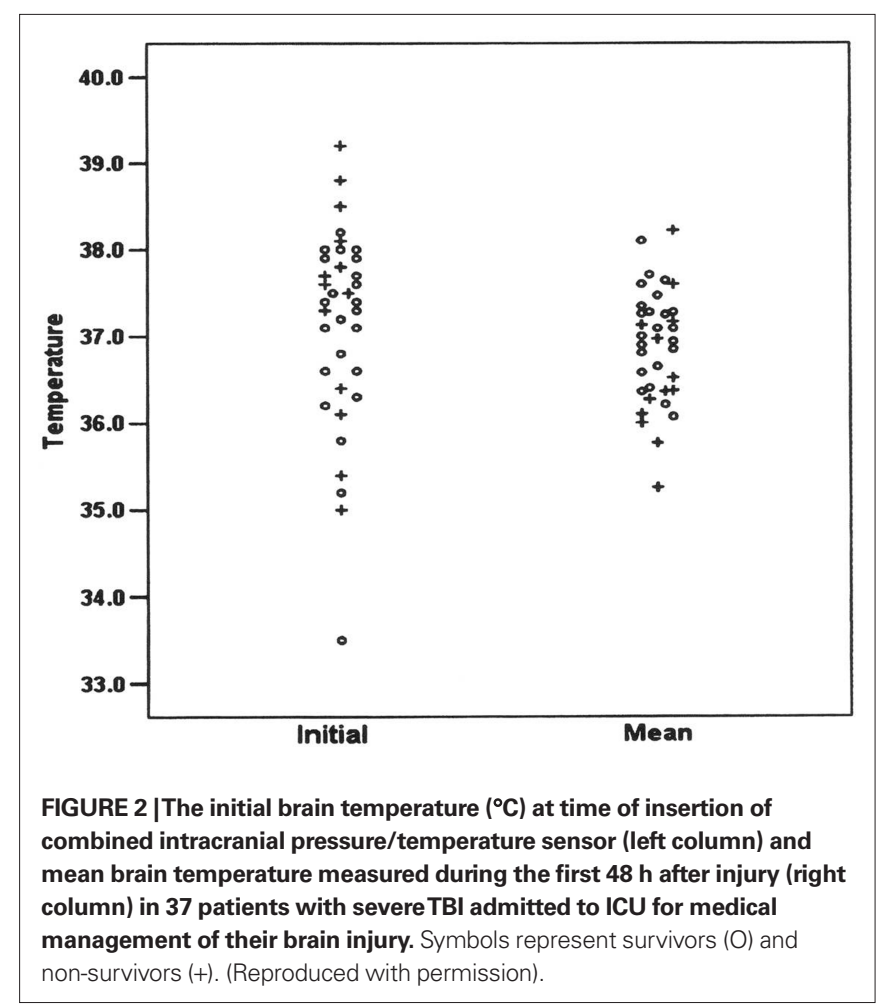


$1-2^{\circ} \mathrm{C}$ rise in temperature commonly thought to cause secondary injury in the damaged (ischemic) brain is deleterious for all patients with severe TBI.

\section{PROCESS: QUESTIONS POSED AT THE ROUNDTABLE WORKSHOP}

Having discussed the background literature and debated the role of temperature in the injured human brain, the participants worked together in four groups to discuss two issues relevant to neurocritical care management after TBI:

(a) What should future recommendations for temperature measurement be: direct measurement of brain temperature or body core temperature surrogates? (b) Should therapeutic control of temperature be advocated as a treatment panacea or "on prescription"?

From the discussions, the participants arrived at a level of agreement for each issue and the summary opinion provided the basis for this consensus document (Table 2).

The conclusions drawn from the meeting were: there is, as yet, no robust scientific data to support the use of therapeutic control of temperature by induction of hypothermia in patients whose ICP is controllable using standard therapy. A randomized clinical trial is justified to establish if body cooling for control of pyrexia (to normothermia) vs moderate pyrexia leads to a better patient outcome for TBI patients.

Table 2 | Summary of workshop discussions and the participants' recommendations and consensus.

\begin{tabular}{|c|c|c|c|c|}
\hline Workshop objective & Discussion points & Concerns expressed & Recommendations & Consensus \\
\hline $\begin{array}{l}\text { To discuss future } \\
\text { recommendations for } \\
\text { temperature } \\
\text { measurement in } \\
\text { patients with severe } \\
\text { TBI. }\end{array}$ & $\begin{array}{l}\text { Do opportunities exist } \\
\text { for improvement in } \\
\text { measurement accuracy? } \\
\text { What are the range of } \\
\text { differences between } \\
\text { brain and body } \\
\text { temperature and how } \\
\text { much do they vary?: see } \\
\text { Kirk et al. (2009) } \\
\text { What are the benefits of } \\
\text { brain temperature } \\
\text { monitoring? }\end{array}$ & $\begin{array}{l}\text { Value of common body } \\
\text { temperature sites (Johnston et al., } \\
2006 \text {; axilla/skin folds/rectal/ } \\
\text { oesophageal) as surrogates for } \\
\text { brain temperature should be } \\
\text { questioned due to poor } \\
\text { measurement practice } \\
\text { No published guidelines available } \\
\text { for standardization of depth (or } \\
\text { positioning) of the brain } \\
\text { temperature sensor } \\
\text { In view of evidence that } \\
\text { differences exist between brain } \\
\text { and body temperature, this should } \\
\text { be sufficient justification for direct } \\
\text { brain temperature monitoring }\end{array}$ & $\begin{array}{l}\text { Need for improved } \\
\text { measurement reliability in } \\
\text { thermometry practice } \\
\text { Support for greater use of } \\
\text { multi-modality monitoring } \\
\text { If the objective of } \\
\text { neuro-monitoring is to } \\
\text { prevent secondary } \\
\text { damage-"normal" brain } \\
\text { rather than "damaged" } \\
\text { brain tissue should be the } \\
\text { focus for monitoring } \\
\text { A possible benefit of brain } \\
\text { temperature monitoring is } \\
\text { the potential to "titrate" } \\
\text { brain temperature to ICP }\end{array}$ & $\begin{array}{l}\text { Standardization in temperature } \\
\text { measurement is a key } \\
\text { objective for the future } \\
\text { Lack of confidence in rectal } \\
\text { temperature as a surrogate for } \\
\text { brain temperature is attributed } \\
\text { to poor measurement practice } \\
\text { notably: site and depth of } \\
\text { thermistor insertion. } \\
\text { Brain temperature monitoring } \\
\text { should be encouraged as a } \\
\text { "gold" standard if intracerebral } \\
\text { monitoring is warranted } \\
\text { Goal for the future: to build a } \\
\text { body of evidence on brain } \\
\text { temperature about absolute } \\
\text { and trend change differences } \\
\text { between brain and different } \\
\text { core sites } \\
\text { There is a need to understand } \\
\text { the role of brain temperature as } \\
\text { a biomarker for outcome }\end{array}$ \\
\hline $\begin{array}{l}\text { To discuss whether } \\
\text { therapeutic control of } \\
\text { temperature should be } \\
\text { advocated as a } \\
\text { treatment panacea or } \\
\text { undertaken "on } \\
\text { prescription" }\end{array}$ & $\begin{array}{l}\text { What is the evidence } \\
\text { that therapeutic control } \\
\text { of body/brain } \\
\text { temperature is beneficial } \\
\text { for all neurosurgical } \\
\text { patients? }\end{array}$ & $\begin{array}{l}\text { The effect of not cooling patients } \\
\text { with high brain temperature (i.e., } \\
>39^{\circ} \mathrm{C} \text { ) on survival of injured } \\
\text { neurones is unknown. } \\
\text { Treatments/ therapies to } \\
\text { manipulate brain/body temperature } \\
\text { to normal/below normal, levels are } \\
\text { justified only as an adjunct therapy }\end{array}$ & $\begin{array}{l}\text { Overwhelming support was } \\
\text { given to a more } \\
\text { "prescriptive" or "tailored" } \\
\text { approach to the use of } \\
\text { cooling interventions } \\
\text { Patients with refractory ICP } \\
\text { may benefit from body } \\
\text { cooling. }\end{array}$ & $\begin{array}{l}\text { The "selection" of patients for } \\
\text { therapeutic hypothermia was a } \\
\text { preferred approach to } \\
\text { temperature management } \\
\text { Whole body/internal cooling is } \\
\text { not justifiable for temperature } \\
\text { control per se. }\end{array}$ \\
\hline
\end{tabular}
for those patients with refractory intracranial hypertension where clinicians are "struggling" to gain control of pressure increases within the brain.

\footnotetext{
The effect of not cooling patients with high brain temperature (i.e., $>39^{\circ} \mathrm{C}$ ) on survival of injured

Treatments/ therapies to manipulate brain/body temperature cooling.
The "selection" of patients for therapeutic hypothermia was a preferred approach to mperature management
Who body/internal cooling is not justifiable for temperature

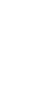




\section{ACKNOWLEDGMENTS}

Our thanks go to the Manchester Conference delegates and workshop participants': Iain Chambers, Paul Dark, Ian Geraghty, Chris Griffiths, Arun Gupta, Stephen Hopkins, Nicola Johnston, Andrew King, Andrew Levick, Richard Protheroe, Raphael Sacho, Martin Smith, Gareth Thomas, Christos Tolias, Pippa Tyrrell, Andy Vail, Elena Vescovo, Chris Whitehead. We also with to thank Dr Dannielle Kirk, Dr Anna McGlone, Mrs Sharon Hulme, and Ms Nicole Burden, who kindly transcribed the workshop discussions. I would also like to thank Mrs Denise Fieldhouse for facilitating the afternoon workshop and for her clarity and drive in helping achieve our consensus statement. My sincere thanks also go to my colleague, Mr Timothy Rainey for his help and assistance with the conference organization. Thanks are also due to the generous support of our sponsors; Irwin Mitchell Solicitors, Integra Neurosciences, Raumedic ${ }^{\oplus}$, Eden Medical Ltd and Lambda photometrics. Thanks are also due to Dr Chen Nan for assistance with data analysis. I would like to thank all the speakers and participants for helping make the day a rewarding and successful venture.

\section{REFERENCES}

Abate, M. G., Cadore, B., and Citerio, G. (2008). Hypothermia in adult neurocritical care patients: a very "hot" strategy not to be hibernated yet! Minerva Anestesiol. 74, 425-430.

Aiyagari, V., and Diringer, M. N. (2007). Fever control and its impact on outcomes: what is the evidence? J. Neurol. Sci. 261, 39-46.

Andrews, P. J., Sleeman, D. H., Statham, P. F., McQuatt, A., Corruble, V., Jones, P. A., Howells, T. P., and Macmillan, C. S. (2002). Predicting recovery in patients suffering from traumatic brain injury by using admission variables and physiological data: a comparison between decision tree analysis and logistic regression. J. Neurosurg. 97, 326-336.

Bernabei,A. F., Levison, M.A., and Bender, J. S. (1992). The effects of hypothermia and injury severity on blood loss during trauma laparotomy. J. Trauma. 33, 835-839.

Brinnel, H., Cabanac, M., and Hales, J. R. S. (1987). "Critical upper levels of body temperature, tissue thermosensitivity and selective brain cooling in hyperthermia," In Heat Stress: Physical Exertion and Environment, eds I. R. S. Hales and D. A. B. Richards (Amsterdam: Excerpta Medica), 209-240.

Bullock, R. M., and Povlishock, J. T. (2007). Guidelines for the management of severe traumatic brain injury. Brain trauma foundation guidelines. $J$. Neurotruma 24(Suppl. 1), S-1-S-106.

Busto, R., Dietrich, W. D., Globus, M. Y-T., Scheinberg, P., and Ginsberg, M. D. (1987). Small differences in intraischemic brain temperature critically determine the extent of ischaemic neuronal injury. J. Cereb. Blood Flow Metab. 7, 729-738.

Childs, C. (2008). Human brain temperature: regulation, measurement and relationship with cerebral trauma: part 1. Br. J. Neurosurg. 22, 486-496.

Childs, C., Hiltunen, Y., Patankar, T., and Kauppinen, R. (2007). Determination of regional brain temperature using proton magnetic resonance spectroscopy to determine brain-body temperature differences in healthy human subjects. Magn. Reson. Med. 57, 59-66.

Childs, C., and Machin, G. (2009). Reliability issues in human brain temperature measurement. Crit. Care 13, R106. doi: 10.1186/cc7943.

Childs, C., Sacho, R. H., and King, A. T. (2009). Brain hyperthermia after traumatic brain injury does not reduce brain oxygen (letter to the editor). Neurosurgery 64(3), E577.

Childs, C., Vail, A., Leach, P., Rainey, T., Protheroe, R., and King, A. (2006). Brain temperature and outcome after severe traumatic brain injury. Neurocrit. Care 5, 1-5.

Childs, C., Vail, A., Protheroe, R., King,A.T., and Dark, P. M. (2005). Differences between brain and rectal temperature during routine critical care of patients with severe traumtic brain injury. Anaesthesia 60, 759-765.

Clifton, G. L., Choi, S. C., Miller, E. R., Levin, H. S., Smith, Jr. K. R., Muizelaar, J. P., Wagner, Jr. F. C., Marion, D. W., and Luerssen, T. G. (2001). Lack of effect of induction of hypothermia after acute brain injury. N. Engl. J. Med. 344, 556-563.

Coles, J. P. (2004). Regional Ischaemia after head injury. Curr. Opin. Crit. Care 10, 120-125.

Cook, D. J., Guyatt, G. H., Laupacis, A., Sackett, D. L., and Goldberg, R. J. (1995). Clinical recommendation using levels of evidence for antithrombotic agents. Chest 108, 227-230.

Cremer, O. L., and Kalkman, C. J. (2007). Cerebrla pathophysiology and clinical neurology of hyperthermia in humans. Prog. Brain Res. 162, 153-169.

DuBois, E. F. (1949). Why are fever temperatures over $106 \mathrm{oF}$ rare? Am. J. Med. Sci. 27, 361-368.

Endress, M., Engelhardt, B., Koistinaho, J., Lindvall, O., Mearis, S., Mohr, J. P., Planas, A., Rothwell, N., Schwaninger, M., and Schwab, M.
E. (2008). Improving outcome after stroke: overcoming the translational Medicine roadblock. Cerebrovasc. Dis. 25, 268-278.

Geffroy, A., Bronchard, R., Merckx, P., Seince, P. F., Faillot, T., Albaladejo, P., and Marty, J. (2004). Severe traumatic head injury in adults: which patients are at risk of hyperthermia? Intensive Care Med. 30, 785-790.

Goss, J. R., Styren, S. D., Miller, P. D., Kochanek, P. D., Palmer, A. M., Marion, D. W., and DeKosky, S. T. (1995). Hypothermia attenuates the normal increase in interleukin lbeta NNA and nerve growth factor following traumatic brain injury in the rat. $J$. Neurotrauma 12, 159-167.

Grande, P.-O., Reinstrup, P., and Romner, B. (2009). Active cooling in traumatic brain-injured patients: a questionable therapy? Acta Anesthesiol. Scand. 53, 1233-1238.

Greer, D. M., Funk, S. E., Reaven, N. L., Ouzounelli, M., and Uman, G. C. (2008). Impact of fever on outcome in patients with stroke and neurological injury. Stroke 39, 3029-3035.

Griesman, L. A., and Mackowiak P. A. (2002). Fever: beneficial and detrimental effects of antipyretics. Curr. Opin. Infect. Dis. 15, 241-245.

Gupta, A. K., Al-Rawi, P. G., Hutchinson, P. J., and Kirkpatrick, P. J. (2002). Effect of hypothermia on brain tissue oxygenation in patients with severe brain injury. Br. J. Anesth. 88, 188-192.

Haveman, J., Sminia, P., Wondergem, J., Van Der Zee, J., and Hulshof, M. C. C. M. (2005). Effects of hyperthermia on the central nervous system: what was learnt from animal studies? Int. J. Hyperthermia 21, 473-487.

Henker, R. A., Brown, S. D., and Marion, D. W. (1998). Comparison of brain temperature with bladder and rectal temperatures in adults with severe head injury. Neurosurgery 42, 1071-1075.

Hutchinson, J. S., Ward, R. E., Lacroix, J., Hebert, P. C., Barnes, M. A., Bohn, D. J., Dirks, P. B., Doucette, S., Fergusson, D.,
Gottesman, R., Joffe,A. R., Kirpalani,H. M., Meyer, P. G., Morris, K. P., Moher, D., Singh, R. N., and Skippen, P. W. (2008). Hypothermia theraphy after traumatice brain injury in children. $N$. Engl. J. Med. 358, 2447-2456.

Jeremitsky, E., Omert, L., Dunham, M., Protech, J., and Rodtiguez, A. (2003). Harbingers of poor outcome the day after severe brain injury: hypothermia, hypoxia and hypotension. J.Trauma 54, 312-319.

Johnston, N. J., King, A. T., Protheroe, R., and Childs, C. (2006). Body temperature management after severe traumatic brain injury: methods and protocols usd in the United Kingdom and Ireland. Resuscitation 70, 254-262.

Jones, P. A., Andrews, P. J. D., Midgley, S., Anderson, S. I., Piper, I. R., Tocher, J. L., Housley, A. M., Corrie, J. A., Slattery, J., Dearden, N. M., and Miller, J. D. (1994). Measuring the burden of secondary insults in head-injured patients during intensive care. J. Neurosurg. Anesthesiol. 6, 4-14.

Kilpatrick, M. M., Lowry, D. W., Firlik, A. D., Yonas, H., and Marion, D. W. (2000). Hyperthermia in the neurosurgical intensive care unit. Neurosurgery 47, 850-856.

Kim,Y., Busto, R., Dietrich,W.D., Kraydieh, S., and Ginsberg, M.D. (1996). Delayed postischaemic hyperthermia in awake rats worsens the histpathological outcome of transient focal ischaemia. Stroke 27, 2274-2281.

Kirk, D., Rainey, T., Vail, A., and Childs, C. (2009). Infra-red thermometry: the reliability of tympanic and temporal artery readings fro predicting brain temperature after severe traumatic brain injury. Crit. Care 13, R81. doi: 10.1186/cc7898.

Kluger, M. J. (1979). Fever: Its Biology, Evolution and Function. Princeton: Princeton University Press.

Lyden, P. D., Krieger, D., Yenari, M., and Dietrich, W. D. (2006). Therapeutic hypothermia for acute stroke. Int. J. Stroke 1, 9-19. 
Lyon, R. M., Robertson, C. E., and Clegg, G. R. (2010). Therapeutic hypothermia in the emergency department following out-of-hospital cardiac arrest. Br. Med. J. 27, 418-423.

Maas, A. I., Dearden, M., Teasdale, G. M., Braakman, R., Cohadon, F., Iannotti, F., Karimi, A., Lapierre, F., Murray, G., Ohman, J., Persson, L., Servadei, F., Stocchetti, N., and Unterberg, A. (1997). EBIC-guidelines for management of severe head injury in adults. European Brain Injury Consortium. Acta Neurochir. (Wien) 139, 286-294.

Maas, A. I. R., Marmarou, A., Murray, G. D., Teasdale, T. W., and Steyerberg, E. W. (2007). Prognosis and clinical trial design in traumatic brain injury: the IMPACT study. J. Neurotrauma 24, 232-238.

Machin, G., and Childs, C. (2010).A systematic performance evaluation of brain and body temperature sensors using ultra-stable temperature references. J. Med. Eng. Technol. 34, 192-199.

Manno, E. M., and Farmer, J. C. (2004). Acute brain injury: if hypothermia is good, then is hyperthermia bad? Crit. Care Med. 32, 1611-1612.

Martini, W.Z. (2007). The effects of hypothermia on fibrinogen metabolism and coagulation function in swine. Metab. Clin. Exp. 56, 214-221.

McHugh, G. S., Butcher, I., Steyerberg, E. W., Lu, J., Mushkudiani, N., Marmarou, A., Maas, A. I. R., and Murray, G. D. (2007). Statistical approaches to the univariate prognostic analysis of the IMPACT database on traumatic brain injury. J. Neurotrauma 24, 251-258.

McQuatt, A. (1998). Using Machine Learning Techniques to Predict Clinical Ooutcome. MD Thesis, Edinburg University, Edinburgh.

Mekjavic, I. B., and Eiken, O. (2006). Contribution of thermal and nonthermal factors to the regulation of body temperature in humans. J. Appl. Physiol. 100, 2065-2072.

Mellergard, P. (1994). Monitoring of rectal, epidural, and intraventricular temperature in neurosurgical patients. Acta Neurochir. 60, 485-487.

O'Grady, N. P., Barie, P. S., Bartlett, J., Bleck, T., Garvey, G., Jacobi, J., Linden, P., Maki, D. G., Nam, M., Pasculle, W., Pasquale, M. D., Tribett, D. L., and Masur, H. (1998). Practice parameters for evaluating new fever in critically ill adult patients. Crit. Care Med. 26, 392-408.

Peterson, K., Carson, S., and Carney, N. (2008). Hypothermia treatment for traumatic brain injury: a systematic review and meta-analysis. J. Neurotrauma 25, 62-71.
Preston-Thomas, H. (1990). The international temperature scale of 1990 (ITS90). Metrologia 27, 3-10.

Reith, J., Jorgensen, H. S., Pederson, P. M., Nakayama, H., Raaschou, H. O., Jeppesen, L. L., and Olsen, T. S. (1996). Body temperature in acute stroke: relation to stroke severity, infarct size, mortality and outcome. Lancet 347 , 422-425.

Romanovsky, A. A., and Szekely, M. (1998). Fever and hypothermia: two adaptive thermoregulatory responses to systemic inflammation. Med. Hypotheses 50, 219-226.

Rossi, S., Zanier, E. R., Mauri, I., Colombo, A., and Stocchetti, N. (2001). Brain temperature, body core temperature and intracranial pressure in acute cerebral damage. J. Neurol. Neurosurg. Psychiatr. 71, 448-454.

Rumana, C. S., Gopinath, S. P., Uzura, M., Valadka, A. B., and Roberston, C. S. (1998). Brain temperature exceeds systemic temperature in head-injured patients. Crit. Care Med. 26, 562-567.

Sacho, R. H. Vail, A, Rainey, T., King, A. T., and Childs, C. (2010). The effect of spontaneous alterations in brain temperature in outcome: a prosepctive observational cohort study in patients with severe traumatic brain injury. J. Neurotrauma. doi: 10. 1089/ neu.2010.1384 [ahead of print].

Sacho, R. S., and Childs, C. (2008). The significance of altered temperature after traumatic brain injury: an analysis of investigations in experimental and human studies: part 2. Br. J. Neurosurg. 22, 497-507.

Schulman, C. I., Namias, N., Doherty, J., Manning, R. J., Li, P., Alhaddad, A., Lasko, D., Amortegui, J., Dy, C. J., Dlugasch, L., Baracco, G., and Cohn, S. M. (2005). The effect of antipyretic therapy upon outcomes in critically ill patients: a randomised controlled trial. Surg. Infect. 6, 369-375.

Schwab, S., Schwartz, S., Aschoff, A., Keller, E., and Hacke, W. (1998). Moderate hypothermia and brain temperature in patients with severe middle cerebral artery infarction. Acta Neurochir. 71, 131-134.

Seule,M.A., Muroi,C.,Mink, S., Yonekawa, Y., and Keller, E. (2009). Therapeutic hypothermia in patients with aneurysmal subarachnoid hemorrhage, refractory intracranial hypertension, or cerebral vasospasm. Neurosurgery 64, 86-93.

Shankaran, S., Pappas, A., Laptook, A. R., McDonald, S. A., Ehrenkranz, R. A., Tyson, J. E., Walsh, M., Goldberg, R.
N., Higgins, R. D., and Das, A. (2008) Outcomes of safety and effectiveness in a multicenter randomized, controlled trial of whole body hypothermia fro neonatal hypoxi-ischaemic encephalopathy. Pediatrics 122, e791-e798.

Sharma, H. S., Hoopes, P. J. (2003) Hyperthermia induced pathophysiology of the central nervous system. Int J. Hyperthermia 19, 325-354.

Soukup, J., Zauner, A., Doppenberg, E. M. R., Menzel, M., Gilman, C., Young, H. F., and Bullock, R. (2002). The importance of brain temperature in patients with severe head injury: relationship to intracranial pressure, cerebral perfusion pressure, cerebral blood flow and outcome. J. Neurotrauma 19, 559-571.

Spiotta, A. M., Stiefel, M. F., Heuer, G. C., Bloom, S., Maloney-Wilensky, E., Yang, W., Grady, M. S., and LeRoux, P. D. (2008). Brain hyperthermia after traumatic brain injury does not reduce brain oxygen. Neurosurgery 62 , 864-872.

Stocchetti, N., Protto, A., Lattuada, M., Magnoni, S., Longhi, L., Ghisoni, L., Egidi, M., and Zanier, E. R. (2005). Impact of pyrexia on neurochemistry and cerebral oxygenation after acute brain injury. J. Neurol. Neurosurg. Psychiatr. 76, 1135-1139.

Stocchetti, N., Rossi, S., Zanier, E. R., Colombo, A., Beretta, L., and Citerio, G. (2002). Pyrexia in head injured patients admitted to intensive care. Intensive Care Med. 28, 1555-1562.

Stone, J. G., Young, W. L., Smith, C. R., Solomon, R.A., Wald, A., Ostapkovich, N., and Shrebnick, D. B. (1995). Do standard monitoring sites reflect true brain temperature when profound hypothermia is rapidly induced and reversed? Anaesthesiology 82, 344-351.

Stoner, H. B. (1974). Inhibition of thermoregulatory non-shivering thermogenesis by trauma in cold-acclimated rats. J. Physiol. 238, 657-670.

Sydenham, E., Robers, I., and Alderson, P. (2009). Hypothermia for traumatic head injury. Cochrane Database Syst. Rev. CD001048.

Thompson, H. J., Pinto-Martin, J., and Bullock, M. R. (2003). Neurogenic fever after traumatic brain injury: an epidemiologocal study. J. Neurol. Neurosurg. Psychiatr. 74, 614-619.

Tokutomi, T., Miyagi, T., Morimoto, K., Karukaya, T., and Shigemori, M. (2004). Effect of hypothermia on serum electrolyte, inflammation, coagulation and nutritional param- eters in patients with severe traumatic brain injury. Neurocrit. Care 1, 171-182.

Van Der Zee, J., Vujaskovic, Z., Kondo, M., and Sugahara, T. (2008). The Katoda Fund International Forum 2004-clinical group comsensus. Int. J. Hyperthermia 24, 111-122.

Vescovo, E., Levick, A. P., Childs, C., Zhao, S., Machin, G., Rainey, T., and Williams, S. R. (2010). High precision calibration of MRS thermometry using validated temperature standards. Proc. Int. Soc. Magn. Reson. Med. (in press).

Vespa, P., Bergsneider, M., Hattori, N., Wu, H.-M., Hiang, S.-C., Martin, N. A., Glenn, T. C., McArthur, D. L., and Hovda, D. A. (2005). Metabolic crisis without brain ischaemia is common after traumatic brain injury: a combined microdialysis and positron emission tomography study. J Cereb. Blood Flow Metab. 25, 763-774.

Wieloch, T., and Nikolich, K. (2006). Mechanisms of neuronal plasticity following brain injury. Curr. Opin. Neurobiol. 16, 258-264.

Yanamoto, H., Nagata, I., Nakahara, I., Tohnai, N., Zhang, Z., and Kikuchi, H. (1999). Combination of intraischaemic and postischaemic hypothermia provides potent and persistent neuroprotection against temporary focal ischaemia in rats. Stroke 30 , 2720-2726.

Conflict of Interest Statement: The authors declare that the research was conducted in the absence of any commercial or financial relationships that could be construed as a potential conflict of interest.

Received: 28 September 2010; accepted: 01 November 2010; published online: 23 November 2010.

Citation: Childs C, Wieloch T, Lecky F, Machin G, Harris B and Stocchetti N (2010) Report of a consensus meeting on human brain temperature after severe traumatic brain injury: its measurement and management during pyrexia. Front. Neur. 1:146. doi: 10.3389/ fneur.2010.00146

This article was submitted to Frontiers in Neurotrauma, a specialty of Frontiers in Neurology.

Copyright () 2010 Childs, Wieloch, Lecky, Machin, Harris and Stocchetti. This is an open-access article subject to an exclusive license agreement between the authors and the Frontiers Research Foundation, which permits unrestricted use, distribution, and reproduction in any medium, provided the original authors and source are credited. 